WORLD VIEW

\title{
Corneal grafts at St John Eye Hospital, Jerusalem, January 2001-November 2002
}

\author{
M Claesson, W J Armitage
}

See end of article for

authors' affiliations

Br J Ophthalmol 2004;88:858-860. doi: 10.1136/bjo.2003.035758

Correspondence to:

Dr M Claesson,

Department of

Ophthalmology,

Sahlgrenska University

Hospital, S-431 80

Mölndal, Sweden;

margareta.l.claesson@

vgregion.se

Accepted for publication

7 January 2004

\begin{abstract}
Aim: To compare a cohort of corneal graft patients in east Jerusalem with one in Sweden, concerning diagnosis, sex, patient age, preoperative visual acuity in both eyes, and type of operation.

Methods: Standard forms developed for the Swedish Corneal Transplant Register were used for data collection at the time of operation.

Results: In east Jerusalem, keratoconus accounted for $51 \%$ of the grafts compared with only $27 \%$ in Sweden and the male:female ratio was reversed. There were very few patients with endothelial disease. The Palestinian patients had overall worse visual acuity both in the eye to be operated and the fellow eye compared with patients in Sweden.

Conclusion: Significant differences were found between the Palestinian and Swedish cohorts in the distribution of indications for transplantation and preoperative visual acuity.
\end{abstract}

$\mathrm{S}$ John Eye Hospital, situated in east Jerusalem, is the only eye hospital for the three million Palestinians living in Jerusalem, the West Bank, and Gaza. It is a charity hospital, run by the Order of St John, and dates back to the time of the Crusades.

Apart from intermittent periods of relatively high transplant activity, such as 1988-92, ${ }^{1}$ grafts were done infrequently owing to the lack of a regular supply of tissue. One of us (MC) worked at the hospital as a cornea consultant from January 2001 to November 2002 specifically to establish a cornea unit with the help of a fellow from the United States. Contact was made with Tissue Banks International (TBI) in Baltimore, MD, to supply corneas on a routine basis, usually three per week.

In 1996, a corneal transplant register was established in Sweden. ${ }^{2}$ Cornea registers often concentrate mainly on graft survival and rejection but, as the main reason for grafting is to improve vision, the Swedish register focuses on this particular aspect of graft outcome. From January 2001 to November 2002 all the grafts performed at St John Eye Hospital were added to the Swedish Cornea Transplant Register. The purpose was to create a means of following up the results of the grafts done during this period, both as a quality control, and to learn more about the indications and clinical practice in these different patient populations.

As the healing process in a corneal graft is slow, with suture removal and procedures for correcting remaining astigmatism done typically more than 1 year after transplantation, data in the Swedish register are collected from a 2 year follow up. The eye then has a fairly stable refraction and visual acuity. As the St John patients had not yet reached the 2 year follow up assessment at the time of writing, this paper compares the preoperative data between the Swedish and the Palestinian patients. The 2 year follow up will be reported subsequently.

\section{METHODS}

The forms developed for the Swedish Corneal Transplant Register to report data preoperatively and at 2 years postoperatively were used for data collection at the St John Eye Hospital. The data from Jerusalem were added to the Swedish register, which is held as a custom designed
Access (Microsoft) database. At the time of surgery, patients' details were provided, including age, sex, indication for transplantation, type of procedure, visual acuity, and lens status. The indications were divided into five groups: keratoconus, endothelial disease (including Fuchs'), bullous keratopathy (corneal oedema resulting from previous ocular surgery), stromal dystrophy, and one group containing all the remaining indications. This "other indication" group turned out to be a substantial proportion of the grafts reported previously to the Swedish register. ${ }^{2}$ It was therefore decided that from January 2001 the actual indication in this subgroup should be specified, in both the Swedish and the Jerusalem data. The date and type of surgery were also noted, as well as whether there had been grafts in the fellow eye. The type of surgery was defined as penetrating keratoplasty (PKP), triple procedure (penetrating keratoplasty combined with extracapsular cataract extraction and implantation of an artificial intraocular lens), or "other procedure" (for example, PKP combined with replacement of intraocular lens, secondary intraocular lens, vitrectomy, iris suture, or other reconstructive surgery).

All of the corneas used in St John Eye Hospital were supplied by Tissue Banks International, Baltimore, MD, USA. Unlike the grafts in Sweden, where the eye banks store corneas by organ culture, the corneas supplied by TBI were all stored in Optisol at $4^{\circ} \mathrm{C}$.

At the time of analysis, 3431 grafts had been recorded on the Swedish register, which accounts for $89 \%$ of the grafts performed in Sweden since the register began. At St John, 161 grafts were performed during January 2001-November 2002 and all were reported to the register.

\section{RESULTS}

\section{Indications for transplantation}

The distribution of indications in the two patient groups is shown in figure l. Ages and sex ratios of the different indications are given in table 1 . In both groups, keratoconus was the most frequent indication for grafting. There were, however, clear differences between the Swedish and the Palestinian distributions $(\mathrm{p}<0.001)$. In Sweden, keratoconus constituted $27 \%$ of grafts and the male:female ratio was 75:25. In contrast, keratoconus in the Palestinian group 
Table 1 Diagnosis, age, and sex ratios of corneal transplant patients in St John Eye Hospital and Sweden

\begin{tabular}{|c|c|c|c|c|c|c|c|}
\hline \multirow[b]{2}{*}{ Indication } & \multicolumn{3}{|l|}{ St John } & \multicolumn{3}{|l|}{ Sweden } & \multirow[b]{2}{*}{ p Values } \\
\hline & Age (SD) & No (\%) & $M: F$ & Age (SD) & No (\%) & $M: F$ & \\
\hline Keratoconus & $20.4(7.5)$ & $79(51)$ & $39: 61$ & $38.1(13.4)$ & $928(27)$ & $75: 25$ & $<0.001^{*}$ \\
\hline Endothelial disease & $74.7(9.0)$ & $3(2)$ & - & $72.9(10.4)$ & 589 (17) & $31: 69$ & \\
\hline Bullous keratopathy & $61.1(17.0)$ & $15(10)$ & $60: 40$ & $76.2(10.4)$ & $766(22)$ & $32: 68$ & $<0.001^{*}$ \\
\hline Stromal dystrophy & $53.9(20.2)$ & $7(5)$ & - & $62.9(16.3)$ & $103(3)$ & $40: 60$ & \\
\hline Re-graft & $55.6(20.2)$ & $16(10)$ & $53: 47$ & $61.8(17.0)$ & $325(10)$ & $57: 43$ & $0.7^{*}$ \\
\hline Other & $58.3(21.9)$ & $34(22)$ & $63: 37$ & $60.9(18.0)$ & $720(21)$ & $53: 47$ & $0.2^{*}$ \\
\hline Total & & 154 & & & 3431 & & \\
\hline
\end{tabular}

accounted for $51 \%$ of grafts and the male:female ratio of 39:61 showed a preponderance of females compared with Sweden $(p<0.001)$. Bullous keratopathy was less prevalent in the Palestinian patients and, again, the sex ratio was reversed compared with Sweden where this group was dominated by females $(p<0.001)$. Another difference was found in the endothelial disease group, which accounted for $17 \%$ of grafts in Sweden, but at St John only three of the 161 patients had this condition. The frequencies of regrafts and other indications were similar in east Jerusalem and Sweden, as were the sex ratios in these two groups. Table 2 shows the distribution of the indications in the "other" group in which the leading reason for grafting was corneal scarring of unknown cause.

\section{Type of operation}

In keratoconus, virtually all the operations were straightforward PKP in both the Swedish (93\%) and the Palestinian (98\%) groups. In Sweden, a triple procedure was the main operation type in the endothelial disease group, and stromal dystrophy; but in the Palestinian group there were too few with these indications to draw any conclusions. In "other indication" there was quite a range among the different types of operation.

\section{Visual acuity}

Before surgery $86 \%$ of the Swedish patients and $100 \%$ of the Palestinian patients had visual acuity $\leqslant 0.2$ in the eye to be operated $(\mathrm{p}<0.001$, Fisher's exact test). Overall, $44 \%$ (60 of 137) of the Palestinian patients had a visual acuity in the eye to be grafted as good as or better than the contralateral eye. The corresponding figure for Swedish patients was only $20 \%$. For keratoconus patients alone, $40 \%$ of the Palestinian

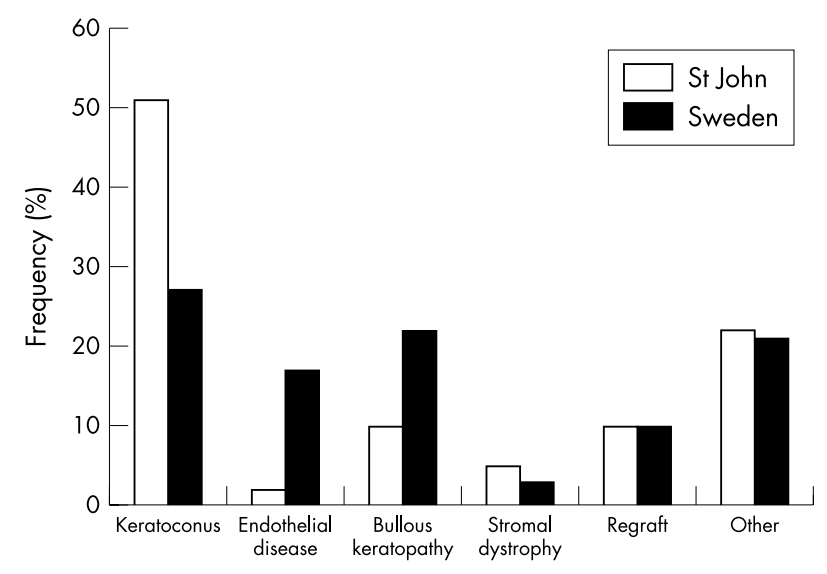

Figure 1 Distribution of indications for corneal transplantation in Sweden $(n=3431)$ and at St John Hospital, Jerusalem $(n=161)$ $\left(\chi_{5}^{2}=63.6, p<0.001\right)$. patients and $11 \%$ of the Swedish patients had visual acuity in the eye to be grafted as good as or better than the contralateral eye.

\section{DISCUSSION}

Corneal transplantation is a routine operation, which is straightforward most of the time. However, the rehabilitation time after surgery is long because of a slow healing process and many of the factors that affect visual outcome are uncertain. There are many reports of graft survival and follow up from Europe, United States, and Australia, ${ }^{2-5}$ but it is equally important to understand the need for corneal transplantation and graft outcome in regions where the socioeconomic conditions are less favourable. It is for this reason that a cohort of 161 grafts from the St John Eye Hospital in Jerusalem has been included in the Swedish Corneal Transplant Register.

Data from St John Eye Hospital patients were added to the Swedish register over a period of 23 months. This should allow direct comparisons to be made between these two patient groups. Furthermore, it is perhaps even more important to have a system of assessing outcome in a clinic like this in east Jerusalem to inform and guide the clinical management of the patients. The patients in the Palestinian territories have more difficulties in coming for treatment and follow up and the impression is that they are at greater risk of postoperative complications. This may be connected with the prevailing poor socioeconomic conditions. It is too early to say anything about the graft outcome, as the 2 year follow up is not yet completed, but when these data are available they will be compared with the Swedish results.

Much can be learned, however, from comparing the preoperative St John data with the Swedish data. It was especially marked that keratoconus was far more frequent in females in the Palestinian patients. Other reports typically show a preponderance of males in the keratoconus group. ${ }^{4}$ However, Kennedy et al, ${ }^{6}$ in a 48 year epidemiological study in Minnesota, found no difference in the actual prevalence of the disease between the sexes in the general population. The data we have from St John Hospital only reflect those patients coming to the hospital for help, not the actual prevalence of the disease in the population. It is uncertain, therefore, whether the cause of this predominance of females

Table 2 Breakdown of "other" indications at St John Eye Hospital

\begin{tabular}{lr}
\hline Diagnosis & No \\
\hline Scar & 21 \\
Herpes simplex virus & 4 \\
Burn & 2 \\
Perforating abscess/ulcer & 5 \\
Corneal laceration & 3 \\
\hline
\end{tabular}


in the keratoconus group is of biological or genetic origin, or whether it simply reflects environmental or social reasons. For example, many of the young women came to the hospital with their parents. They were approaching marriageable age and did not want to be seen as having a visual handicap or even, indeed, glasses.

It is also noteworthy that keratoconus accounted for an even larger proportion of the indications for transplantation in the Palestinian territories than in Sweden. This could simply be a result of the population in the Palestinian territories having a far higher proportion of young people (for example, $>45 \%$ under 14 years and only $3.4 \%$ over 65 years, according to data from the Palestinian National Authority) than in Sweden. This could also explain the extremely low numbers of grafts for primary endothelial disease. Patients with keratoconus at St John also tended to be younger than in Sweden (see table 1) and presented with far more advanced disease (MC, personal observation). This may be connected with the fact that vernal catarrh is much more prevalent in the Palestinian territories, ${ }^{1}$ and it is known that atopic disease is predisposing for keratoconus. ${ }^{7}$ De Cock $^{1}$ also suggested that the high prevalence of allergic eye disease and the expense and impracticability of contact lens wear in the dry and dusty conditions in the region are likely to be contributing factors. That there may be ethnic differences between the Palestinian territories and Sweden in the course of the disease is also a possibility suggested by the observations of Pearson et al, ${ }^{9}$ who reported differences between the main ethnic groups in Leicester, where Asian patients with keratoconus were younger at presentation and received a corneal transplant earlier.

It is clear from the data that the patients at St John were, so far as their vision is concerned, in a worse state when they came for surgery. All of them had a visual acuity $\leqslant 0.2$ in the eye to be operated, compared with $86 \%$ in the Swedish cohort. A higher proportion of the Palestinian patients (44\% versus $20 \%$ in Sweden) had visual acuity in the eye to be operated as good as or better than the fellow eye. As it is usual to want to improve the worse eye by surgery this can probably be explained by one or more of the following:

- Visual acuity in both eyes is equally poor: many of the Palestinian patients had very advanced disease in both eyes and $50 \%$ had visual acuity of counting fingers or worse in both eyes at their first appointment at the hospital

- In $12 \%$ of patients, the fellow eye was blind, beyond possibilities of repair, and the eye to be operated on was so poor that the patient was willing to take the risk of surgery on the only eye

- In some patients the worse eye was judged to have such poor prognosis because of massive corneal vascularisation or other ocular pathology that the patient was advised to have the better eye grafted.

The keratoconus in the patients at St John was often very advanced, with extreme thinning, large central scars, and sometimes vascularisation. Some had, as mentioned earlier, severe vernal catarrh, which was often difficult to treat. Six patients presented with severely inflamed eyes, five of them had perforated corneas. An emergency graft had to be performed to save the eye under these circumstances. Factors such as these are likely to increase the postoperative risks, so it will be important to see whether this is reflected in the 2 year follow up data.

As data continue to be reported to the Swedish Corneal Transplant Register, it is expected that different questions will be formulated and answered on the basis of clinical evidence, both in Sweden and at the St John Eye Hospital in Jerusalem. This process should lead to better understanding of the factors that influence the visual outcome of corneal transplantation in these two populations and thereby improve the postoperative management of grafts.

\section{ACKNOWLEDGEMENTS}

We thank the dedicated and professional staff at the St John Eye Hospital, Jerusalem. Without the support from Tissue Banks International, delivering corneas of high quality on a regular basis, corneal transplantation at the St John Eye Hospital would not have been possible during the period of this study.

\section{Authors' affiliations}

M Claesson, Department of Ophthalmology, Sahlgrenska University Hospital, S-431 80 Mölndal, Sweden

W J Armitage, Division of Ophthalmology, University of Bristol, Bristol BS1 2LX, UK

Series editors: W V Good and S Ruit

\section{REFERENCES}

1 De Cock R. Penetrating keratoplasty in the West Bank and Gaza. Eye 1994:8:29-34.

2 Claesson M, Armitage WJ, Fagerholm P, et al. Visual outcome in corneal grafts: a preliminary analysis of the Swedish Corneal Transplant Register. Br J Ophthalmol 2002;86:174-80.

3 Williams KA, Muehlberg SM, Bartlett CM, et al, eds. Corneal graft register 1999 report. Adelaide, 2000.

4 Vail A, Gore SM, Bradley BA, et al. Conclusions of the corneal transplant follow up study. Br J Ophthalmol 1997;81:631-6.

5 Dobbins KRB, Price FW, Whitson WE. Trends in the indication for penetrating keratoplasty in the midwestern United States. Cornea 2000;19:813-16.

6 Kennedy RH, Bourne WM, Dyer JA. A 48-year clinical and epidemiologic study of keratoconus. Am J Ophthalmol 1986;101:267-73.

7 Khan MD, Kundi N, Saeed N, et al. Incidence of keratoconus in spring catarrh. Br J Ophthalmol 1988;72:41-3.

8 Totan Y, Hepsen IF, Cekic O, et al. Incidence of keratoconus in subjects with vernal keratoconjunctivitis: a videokeratographic study. Ophthalmology 2001;108, number 4

9 Pearson AR, Soneji B, Sarvananthan N, et al. Does ethnic origin influence the incidence of severity of keratoconus? Eye 2000;14:625-8. 